\title{
Medalha de ouro! Estudo sobre motivação no trabalho voluntário eventual nos Jogos Olímpicos no Rio de Janeiro
}

\section{Gold medal! Study on motivation in eventual volunteer work in the Olympic Games in Rio de Janeiro}

\author{
HELIO ARAÚJO PEREIRA* \\ CARLOS EDUARDO CAVALCANTE**
}

\section{RESUMO}

Este artigo tem por objetivo identificar os fatores motivacionais dos voluntários eventuais envolvidos com eventos esportivos no Brasil. A parte empírica do artigo tem como lócus os jogos olímpicos realizados no Rio de Janeiro no ano de 2016. Os dados empíricos foram coletados a partir do modelo teórico de Bang e Chelladurai (2009), que começaram o desenvolvimento dessa base teórica nos jogos olímpicos, em Atenas, em 2004. Foi utilizado o método quantitativo de pesquisa, compreendendo a aplicação de 400 questionários junto aos voluntários envolvidos nos jogos olímpicos do Rio de Janeiro. A pesquisa evidenciou, na seguinte ordem, que os maiores fatores motivacionais voltados ao esporte, no Brasil, estão relacionados às variáveis: expressão de valores, amor ao esporte e contatos interpessoais. Observou-se ainda, que a variável motivacional, extrínseco, foi menos relevante para os voluntários.

Palavras-chave: Fatores motivacionais. Voluntário eventual. Esporte. Jogos olímpicos do Rio de Janeiro.

* Mestre em Administração pela Universidade Federal da Paraiba - UFPB helioaraujop@gmail.com .

** Dr. em Administração pela Universidade Federal do Rio Grande do Norte - UFRN, professor de departamento de Pós Graduação em Administração da Universidade Federal da Paraiba- UFPB. cavalcantieduardo@gmail.com . 


\section{Abstract}

This present article aims to identify eventual motivational factors in volunteers who have been involved in sport events here in Brazil. Empirical part in this article has its locus in the Olympic Games held in Rio de Janeiro in 2016. Empiric data have been collected based on Bang and Chelladurai (2009) theoretical model that has started theoretical base development in 2004 Athens Olympic Games. Quantitative research method was used by the application of 400 question forms filled in by volunteers involved in Rio de Janeiro Olympic Games. Research has showed, in the sequence, that major motivational factors towards sport in Brazil are related with the following variables: expression of values, love of sport and interpersonal contacts. It was observed that extrinsical motivational variable has showed to be less relevant to volunteers.

Key-words: Motivational factors. Eventual volunteer. Sport. Rio de Janeiro Olympic Games.

\section{INTRODUÇÃo}

No Brasil, o trabalho voluntário surge a partir do início do século XX, diante da necessidade no auxílio e no controle de epidemias de diversas doenças que acometiam, sobretudo, a população mais carente. Esse trabalho esteve ligado, intrinsecamente, à igreja católica e foi desempenhado, exclusivamente, por mulheres (BARELI e LIMA, 2010). Com o passar do tempo, o trabalho voluntário expandiu-se para diversas áreas da sociedade, entre elas o trabalho voluntário em eventos esportivos (COMITÊ OLÍMPICO INTERNACIONAL - COI (2016) e FEDERAÇÃO INTERNACIONAL DE FUTEBOL - FIFA (2014)).

Os voluntários voltados a eventos esportivos, denominados voluntários eventuais no esporte, são elementos importantes que contribuem para a realização e o sucesso dos eventos voltados à área esportiva. Esse tipo de atividade voluntária vem gerando cada vez mais interesse da população. Segundo dados do Comitê Olímpico Internacional - COI (2016), o número de voluntários que atuaram nas últimas olimpíadas passou de 30 mil nos jogos olímpicos de Barcelona, no ano 1992, para 50 mil voluntários, nos jogos do Rio de Janeiro, em 2016. Em relação a outro grande evento esportivo, a 
copa do mundo, os números são ainda mais expressivos. De acordo com a Federação Internacional de Futebol - FIFA (2014), o número de voluntários inscritos passou de 48 mil na copa do mundo da Alemanha, no ano de 2006, para 130.917 mil voluntários na copa do mundo realizada no Brasil em 2014.

Segundo pesquisa de Breuer e Wicker (2011), só na Alemanha existem 1,85 milhões de pessoas envolvidas em atividades voluntárias em clubes esportivos, chegando ao patamar de 37,2 milhões de horas trabalhadas por voluntários nos eventos esportivos no ano de 2010, indicando um valor monetário de 6,7 bilhões de euros, se fossem realizados por trabalhadores formais. Na Inglaterra, Taylor et al. (2003) afirmam que existem cerca de dois milhões de voluntários relacionados a eventos esportivos, o que contabiliza cerca de 266 milhões de horas dedicadas a esse tipo de atividade voluntária. Nesse mesmo sentido, Doherty (2005) identificou que existem 1.17 milhões de voluntários associados a eventos esportivos no Canadá. Diante disso, torna-se um fator crucial por parte dos gestores de eventos esportivos compreenderem os componentes sobre as motivações dos voluntários voltados a esses eventos e, por conseguinte, ter subsídio para a sua gestão.

Esta pesquisa tem por objetivo identificar os fatores motivacionais dos voluntários eventuais que atuaram nos jogos olímpicos no Rio de Janeiro. Para isso, tomou-se como referência o modelo teórico desenvolvido por Bang e Chelladurai (2009), que investigam a motivação no trabalho voluntário em eventos esportivos, a partir de seis variáveis: "expressão de valores", "contato interpessoal", "orientação de carreira", "desenvolvimento pessoal", "extrínseco" e "amor ao esporte".

Para Hallmann e Harms (2012), a maioria das pesquisas sobre motivação no trabalho voluntário no esporte, em grandes eventos esportivos, foi realizada por Bang e Chelladurai (2009) em vários países da Europa e Canadá. Outros estudos como o de Wang e Wu (2014) e de Hallmann e Harms (2012) também usaram o modelo teórico proposto por Bang e Chelladurai (2009) em seus estudos. Então, a utilização em diversos contextos culturais e a inexistência de um instrumento adaptado à cultura brasileira, justificaram a escolha desse modelo. 
Ancorado na premissa de que esse modelo teórico é bastante empregado em pesquisas em outros países, optou-se por sua utilização nesta pesquisa como forma de identificar quais as motivações dos voluntários brasileiros que atuaram nos jogos olímpicos do Rio de Janeiro.

Ressalta-se, ainda, que o pesquisador pretende desenvolver uma ferramenta sobre motivação no trabalho voluntário eventual em eventos esportivos que retrate as características desse tipo de voluntariado no Brasil. Para isso, faz-se necessário testar o modelo teórico de Bang e Chelladurai (2009), consolidado no exterior. A relevância teórica deste estudo se mostra presente a partir da possibilidade de servir de comparativo teórico para futuras pesquisas atinentes à motivação de voluntários eventuais que atuem em eventos esportivos no Brasil e em outros países.

Estudos como o de Johnston e Twynam (1998), Hallmann e Harms (2012) e Gravilov (2012) analisaram as motivações dos voluntários em eventos esportivos na Europa. Hallmann e Harms (2012) buscaram identificar os fatores motivacionais dos voluntários voltados aos dois principais eventos esportivos da Alemanha, relacionados à equitação e ao handebol. Este estudo concluiu que as motivações diferem dependendo do evento, mas, em ambos os casos, os motivos relacionados aos fatores culturais desses voluntários pesquisados na Alemanha foram elementos de destaque que levaram os voluntários a se engajarem nesses dois eventos esportivos.

Johnston e Twynam (1998) pesquisaram sobre a motivação dos voluntários no campeonato feminino de curling no Canadá. O resultado desta pesquisa mostrou que o principal fator motivacional nesse evento foi a intenção de serem voluntários.

Outro estudo sobre motivação no trabalho voluntário voltado ao esporte foi o de Gravilov (2012), que identificou os fatores motivacionais dos voluntários nos jogos olímpicos de Londres em 2012. Esse autor chegou à conclusão que os principais fatores motivacionais dos voluntários são o envolvimento com o esporte e o orgulho nacional.

Em se tratando de Brasil, percebe-se que é um país que realiza diversos eventos esportivos, tanto no contexto nacional, quanto no internacional todos os anos. Exemplos desses eventos, são: Fórmula 
1, jogos da juventude, campeonato brasileiro de futebol, liga de vôlei, entre outros. Compreender as motivações voluntárias no esporte, poderá contribuir com os organizadores desses eventos, no que diz respeito a gestão e recrutamento de voluntários, preenchendo assim, uma lacuna de pesquisa nessa área.

Essa lacuna, pôde ser evidenciada através de uma pesquisa, realizada em novembro de 2016, com a expressão " Motivação no trabalho voluntário no esporte", no portal da CAPES - Comissão de Aperfeiçoamento de Pessoal do Nível Superior. Este portal de pesquisa engloba as mais importantes revistas relacionadas a pesquisas acadêmicas. Desta pesquisa, foram selecionados 258 artigos sobre trabalho voluntário, mas, em nenhum deles, havia relação com motivação no trabalho voluntário no esporte no Brasil, proposto neste artigo..

Um dos grandes desafios das organizações que trabalham com voluntários é encontrar um equilíbrio na gestão do capital humano disponível (HALLMANN e HARMS, 2012). Para realizar qualquer gestão, é necessário que se disponha de dados que possam contribuir para tomada de decisão voltada à gestão do trabalho voluntário. Em termos práticos, esta pesquisa poderá subsidiar os gestores que organizam eventos esportivos no Brasil a compreender os aspectos motivacionais dos voluntários relacionados a esse grande evento esportivo, os jogos olímpicos.

Nesse contexto, os jogos olímpicos de 2016, conhecidos oficialmente como os jogos da XXXI olimpíada, denominados RIO 2016, foram um evento multiesportivo realizado no segundo semestre de 2016, na cidade do Rio de Janeiro. A olimpíada ocorreu, especificamente, no período de 5 a 21 de agosto de 2016, gerenciada pelo Comitê Olímpico Internacional - COI.

A olimpíada do Rio de Janeiro foi o primeiro evento realizado na América do Sul e o segundo na América Latina em toda a sua história. Com os jogos olímpicos acontecendo no Brasil, seria o momento mais oportuno para a realização desta pesquisa, devido à magnitude do evento alinhado com o objetivo deste artigo. Além de oportuna, esta pesquisa mostrou-se viável a partir de uma literatura que permitiu coletar e analisar os dados pertinentes à pesquisa. 


\section{REFERENCIAL TEÓRICO}

\section{Motivação no trabalho voluntário}

Para Cavalcante (2012), estudo da motivação nas organizações é tema recorrente na área organizacional. Latham e Pinder (2005), afirmam que a motivação é um processo psicológico que contribui para interação entre o individuo e o ambiente no qual ele está inserido. Ressalta-se, dentro desse contexto, as teorias motivacionais clássicas, como a de Maslow e Herzberg. Ainda no entendimento de Tamayo e Pascal (2005), as teorias motivacionais identificam fontes de prazer que o trabalhador encontra no seu ambiente de trabalho e que esta motivação pode advir dos indivíduos, do ambiente laboral ou de ambos.

No entanto, segundo entendimento de Cavalcante (2012), as coincidências com o trabalho voluntario encerram ai. Esse autor argumenta que as teorias usadas para entender a motivação, no contexto voluntário, são outras e seu uso se justificam pela diferença que o trabalhador voluntário tem em relação ao trabalhador formal. As principais diferenças são apontadas por Cnaan e Cascio (1998), que diz respeito a dimensão monetária, o tempo disponibilizado, a possibilidade de fazer parte de várias organizações não governamentais simultaneamente, o recrutamento e a relutância das organizações não governamentais em avaliar o desempenho dos voluntários.

Os voluntários podem ter diferentes motivações para atuarem em atividades voluntárias. Para Bojeanet al. (1994), as pessoas podem buscar atividades voluntárias para satisfazer necessidades que não são atendidas em outro lugar. Em outra perspectiva, Bruno e Fiorillo (2012) apresentam uma abordagem simultânea, atribuindo a influência na motivação do trabalho voluntário a fatores psicológicos intrínsecos e extrínsecos. De acordo com a abordagem de simultaneidade, a oferta de trabalho voluntário deve ser observada com base no papel da motivação psicológica.

Os resultados empíricos dos estudos dos autores mostraram que a motivação intrínseca, que envolve aspectos como idade, renda familiar, bem como, deveres para com familiares e para com o setor específico em que um indivíduo está envolvido, é uma variável 
relevante para identificar pessoas, em determinados grupos sociais, com tendências para atuar como voluntárias.

Segundo o entendimento de Rubin e Thorelli (1984), as motivações para o voluntariado são diversas, podendo ser classificadas em dois tipos: razões altruístas e egoístas. As razões altruístas para o voluntariado são intrínsecas e incluem um desejo de ajudar os outros, autos-sacrifícios, compaixão por outros menos afortunados ou uma contribuição para a justiça social. Os motivos egoístas se relacionam com o interesse próprio do voluntário e inclui o desejo de aprender novas habilidades na preparação para o emprego, a oportunidade de socializar e conhecer outras pessoas e usar o lazer de forma construtiva.

Outros argumentos sobre motivação no trabalho voluntário são apresentados por Pallassi e Vervloet (2011) ao discutirem o fenômeno da motivação por meio dos sentidos da participação voluntária. Eles argumentam que as bases da motivação para o voluntariado residem no sentimento de fazer parte de algo ou de transformar um meio. A participação voluntária, por motivos diversos, como o altruísmo ou o egoísmo, deve ser analisada como uma maneira de o indivíduo satisfazer necessidades sociais, como a valorização de si mesmo pelos outros, a interação social e o pensamento pautado na reflexão ou no aspecto de expressão social.

No entendimento de Anheier e Salamon (1999), existem três fatores motivacionais que levam as pessoas a ser voluntárias: motivos altruístas, instrumentais e de obrigação. Motivos altruístas incluem noções de um sentimento de solidariedade para com os pobres, quando os voluntários se identificam com as pessoas que sofrem na sociedade e, por isso, buscam passar esperança e dignidade por meio do seu trabalho. Motivos instrumentais são definidos como um desejo de ganhar novas experiências e habilidades e fazer algo de valor no tempo livre para atender às pessoas e também para obter satisfação pessoal como voluntário. Por fim, os motivos de obrigação incluem o dever moral e religioso e um desejo de contribuir para a comunidade local configurado por um sentimento de dever político de trazer mudanças para a sociedade. 


\section{Motivação voluntária em eventos esportivos}

Um estudo mais recente e mais detalhado sobre motivação voluntária em eventos esportivos foi executado por Bang e Chelladurai (2009), ao desenvolverem um modelo teórico sobre motivação voluntária para eventos esportivos. O desenvolvimento desse modelo identificou seis dimensões motivacionais que explicaram quais as motivações dos voluntários em eventos esportivos (BANG e CHELLADURAI, 2009). Essas razões foram "expressão de valores", relacionada a razões altruístas, podendo ser comparada à categoria de estudo proposto por Farrell et al. (1998). Em segundo lugar, o "amor pelo esporte", que envolve aspectos voltados ao reconhecimento de desempenho da atividade por prazer. Em terceiro, os "contatos interpessoais", focados na filiação e nos relacionamentos com outras pessoas, representados pela solidariedade em Farrell et al. (1998). Em quarto, "carreira", orientada para a obtenção de experiência e competências práticas e preparação para a carreira. Em quinto lugar, o "crescimento pessoal", que continha crescente autoestima com a experiência e, finalmente, as recompensas "extrínsecas", motivadas por entradas gratuitas nos eventos, camisas e broches ou similares (BANG e CHELLADURAI, 2009). “Expressão de valores" foi muito importante para todos os voluntários, enquanto recompensas extrínsecas ou carreiras, representando razões bastante egoístas, não representaram fatores motivacionais importantes, em termos de motivação voluntária.

Na perspectiva de Koutrou (2014), as pesquisas de campo sugerem que os voluntários em eventos esportivos são motivados por uma variedade de fatores, e o impacto de tais fatores pode variar consideravelmente de um indivíduo para outro. Alguns voluntários podem agir de forma altruísta, motivados pelo desejo de contribuir para a sua comunidade e para o desporto, enquanto outros procuram adquirir experiência específica ou prazer, já que o voluntariado pode ser benéfico no desenvolvimento de carreira, na formação de redes sociais e na possibilidade de fazer amigos. Por conseguinte, isso sugere que uma combinação de fatores é necessária para explicar o comportamento voluntário no esporte.

Pesquisa sobre motivação do voluntário no esporte, realizada por Koutrou (2014), nos jogos olímpicos de Londres (2012), cons- 
tatou que os fatores predominantes motivacionais foram "amor ao esporte", seguido pelo fator de "contatos interpessoais", enquanto a "orientação profissional" e "outras recompensas" foram os fatores menos prevalentes para as decisões individuais dos voluntários nos jogos olímpicos de Londres.

\section{Voluntariado eventual nos esportes}

A literatura sobre voluntariado eventual surge pela primeira vez no início da década de 90, quando Nancy Macduff (1991) sugeriu que havia uma mudança na forma como as pessoas estavam se voluntariando, preferindo oportunidades de voluntariado de curto prazo em vez de oportunidades tradicionais de voluntariado a longo prazo, o que, segundo Styers (2004), define-se como voluntariado eventual a atuação do voluntário em eventos esportivos como os jogos olímpicos, que o caracteriza como voluntário eventual no esporte.

De acordo com Moragas (2001), o voluntário de eventos esportivos é uma pessoa que assume o compromisso individual e filantrópico de colaborar com o melhor de suas habilidades na organização dos acontecimentos, assumindo as responsabilidades delegadas a ele sem receber qualquer forma de pagamento ou recompensa material.

Nos jogos olímpicos realizados no Rio de Janeiro, o Comitê Olímpico Internacional - COI (2016) reconheceu a importância dos voluntários para a realização dos jogos, corroborando o pensamento de Annan (2001) ao afirmar que é importante reconhecer o voluntariado como o principal alicerce do movimento olímpico e a necessidade de promover o desenvolvimento da cultura do voluntariado, a fim de contribuir para a construção de um mundo melhor através da educação do jovem pelo esporte.

A participação dos voluntários no desenvolvimento e execução de grandes eventos esportivos é fundamental. Eles realizam tarefas diversas: acompanham as equipes durante suas estadas na cidade-sede, auxiliam árbitros, juízes e chefes de delegação, atendem aos meios de comunicação, aos convidados especiais e turistas que buscam maiores informações sobre a localidade. Eles podem atuar na segurança, com a imprensa, nos complexos esportivos, na área médica, no setor de alimentação, auxiliando a organização geral (AÑ́, 2003). 
As atribuições do voluntariado em eventos esportivos transcendem as suas atividades específicas nos eventos. Para Tandini (2007), a ação voluntária assume contornos bastante específicos. O voluntário passa a ser um agente da hospitalidade, um interlocutor entre culturas diversas, tendo a responsabilidade de interagir com pessoas de diferentes hábitos, classes sociais e religião, integrando-as ao ambiente do evento.

\section{Modelo teórico (Bang e Chelladurai, 2009).}

Os estudos iniciais para elaboração desse modelo teórico, que aborda os aspectos motivacionais dos voluntários em grandes eventos esportivos, foram iniciados nos jogos olímpicos de Atenas (2004) e consolidados no ano de 2009.Bang e Chelladurai (2009) apontaram 6 (seis) fatores motivacionais em seus estudos, classificados como: "expressão de valores": motivações relacionadas a razões altruístas, "contatos interpessoais": motivações relacionadas à relação com outras pessoas, "orientação na carreira": motivações relacionadas à obtenção de experiência e competências práticas, "crescimento pessoal": motivações relacionadas à crescente autoestima com a experiência, "extrínseco": motivação relacionada à obtenção de vantagens com ingressos e uniformes gratuitos e "amor ao esporte": motivação relacionada ao prazer de participar do evento esportivo. A Figura 1, a seguir, permite visualizar melhor a estrutura do modelo teórico.

Figura 1: Modelo Teórico de Bang e Chelladurai (2009).

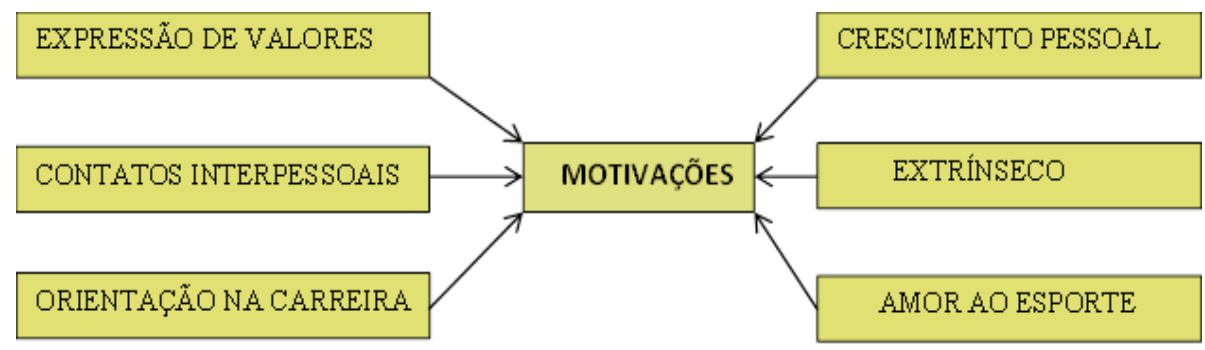

Fonte: Adaptado pelos autores (2017), ancorado no modelo teórico de Bang e Chelladurai (2009). 


\section{Metodologia}

Esta pesquisa é de caráter descritivo, a partir do momento em que expõe os aspectos motivacionais dos voluntários envolvidos nos jogos olímpicos do Rio de Janeiro. No tocante ao método de abordagem, a pesquisa pautou-se no caráter quantitativo, na medida em que avalia as motivações dos voluntários.

O universo da amostra compôs-se de 50 mil voluntários selecionados pelo Comitê Olímpico Internacional - COI (2016). Desse universo, foram aplicados questionários com 400 voluntários. Essa amostragem foi definida por meio do método estatístico desenvolvido por Barbetta (2004), considerando um nível de confiança de 95\% no desenvolvimento da pesquisa, conforme pode ser observado abaixo:

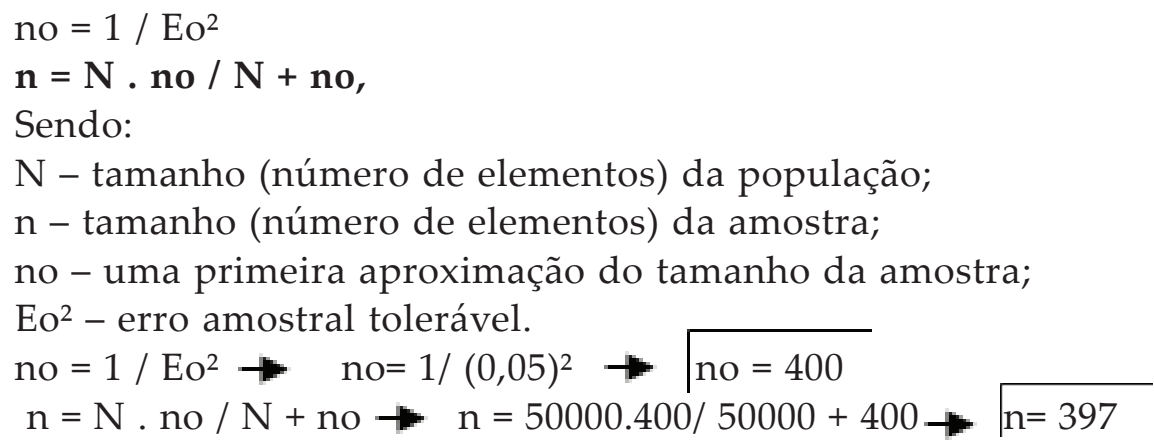

Ressalta-se que o cálculo amostral, apresentou uma amostra de 397 voluntários a serem pesquisados, levando-se em consideração um universo de 50 mil voluntários inscritos no evento. Por uma questão de segurança na amostra da pesquisa, os pesquisadores aplicaram os questionários com 400 voluntários. Essa amostragem foi selecionada a partir do método de amostragem probabilística e organizada pelo método de amostragem estratificada.

Para Barbetta (2004), a amostragem estratificada é utilizada quando a população pode se dividir em subpopulações homogêneas e aleatórias, e possui a vantagem de ser mais eficiente do que os métodos de amostragem simples ou sistemática, pois é mais econômico em termos de tempo e dinheiro, fornecendo resultados com menor probabilidade de erro (BACELAR, 1999). 
No que concerne à coleta de dados, foi utilizado um questionário de pesquisa proveniente do modelo teórico de Bang e Chelladurai (2009), que identifica os aspectos motivacionais de voluntários eventuais associados a eventos esportivos. Essa coleta de dados foi realizada nos locais de eventos esportivos, nos jogos olímpicos do Rio de Janeiro, onde os voluntários estavam executando suas atividades, no período compreendido entre 5 e 21 de agosto de 2016.

Para tratamento dos dados da pesquisa, foram realizadas análises estatísticas por meio de medidas relacionadas à média amostral, desvio padrão, coeficiente de variância, ANOVA e T-test. O desvio padrão é uma medida de dispersão dos valores de uma distribuição normal em relação à sua média; no que concerne ao coeficiente de variância, Pimentel Gomes (2000) diz que, nos experimentos de campo, se o coeficiente de variância for inferior a $10 \%$, entende-se que esse coeficiente de variância é baixo, ou seja, o experimento tem alta precisão; de $10 \%$ a $20 \%$, são considerados médios e de boa precisão; de $20 \%$ a $30 \%$, alto, com baixa precisão, e, acima de $30 \%$, muito alto.

A Tabela 1, a seguir, se refere às variáveis e descrições do instrumento de pesquisa utilizadas neste estudo.

Tabela 1: Visão geral das variáveis motivacionais dos voluntários em eventos esportivos

\begin{tabular}{|c|c|c|}
\hline Variáveis & Descrição & Escala \\
\hline \multicolumn{3}{|c|}{ Motivações (Escala de Likert: de $1=$ Discorda total até $10=$ Concorda total) } \\
\hline Valores 1 & Quero ajudar no que for possível & Numérica \\
\hline Valores 2 & Quero fazer algo que valha a pena & Numérica \\
\hline Valores 3 & Sinto que é importante ajudar outros & Numérica \\
\hline Valores 4 & Quero ajudar a tornar o evento um sucesso & Numérica \\
\hline Valores 5 & Voluntariado ajuda a criar uma sociedade melhor & Numérica \\
\hline Interpessoal 1 & Quero interagir com outras pessoas & Numérica \\
\hline Interpessoal 2 & Quero trabalhar com pessoas diferentes & Numérica \\
\hline Interpessoal 3 & Quero encontrar e conhecer novas pessoas & Numérica \\
\hline Interpessoal 4 & Quero desenvolver relacionamento com outros & Numérica \\
\hline Carreira 1 & $\begin{array}{l}\text { Trabalhar em voluntariado dará uma boa } \\
\text { impressão ao meu currículo }\end{array}$ & Numérica \\
\hline
\end{tabular}




\section{Variáveis}

Motivações (Escala de Likert: de 1 = Discorda total até 10 = Concorda total)

Carreira 2

Quero adquirir alguma experiência prática

Numérica

Carreira 3

Quero fazer novos contatos que poderão ajudar em

Numérica minha carreira

Carreira 4

Quero adquirir experiências de trabalho

Numérica

Carreira 5

Quero adquirir experiências que poderão

Numérica ser úteis em qualquer área

Crescimento 1 Voluntariado me faz sentir necessário

Numérica

Crescimento 2 Posso explorar minhas próprias potencialidades

Numérica

Crescimento 3 Voluntariado me faz sentir importante

Numérica

Crescimento 4 Voluntariado permite adquirir uma nova perspectiva Numérica sobre as coisas

Extrínseco 1 Quero adquirir uniformes e produtos licenciados

Numérica

Extrínseco 2

Quero adquirir tickets e entradas francas

Numérica

Esporte 1

Gosto de qualquer evento relacionado a esportes

Numérica

Esporte 2

Gosto de qualquer evento relacionado a estes esportes Numérica (handebol ou equitação)

Esporte 3 Esporte é algo que eu amo

Numérica

Esporte 4 Adoro estar envolvido em atividades esportivas

Numérica

Comportamentos futuros

Evento Futuro: Vou me engajar em outro evento esportivo no

Fictícia futuro como um voluntário.

Clube Futuro: Vou me associar a um clube esportivo no futuro

Fictícia como uma voluntária

\section{Variáveis sóciodemográficas}

Gênero Gênero do participante $(1=$ feminino, $0=$ masculino $) \quad$ Fictícia

Idade Idade (em anos)

Métrico

Educação

( 1 = fundamental; 2 = ensino médio; 3 = ensino

Fictícia

superior 4 = pós-graduação)

Jornada

Quantas horas trabalha por semana como

Métrico voluntário no evento?

Renda Renda líquida mensal $(0=$ não possui salário; $1=$ até um salário, $2=$ entre 1 e 3 salários, $3=$ entre 3 e 5 salários, $4=$ acima de 5 salários.

Fonte: Adaptado pelos autores (2017), baseado no modelo teórico de Bang e Chelladurai (2009) 


\section{Discussões e ANÁlise dos RESUltados}

A seguir serão apresentadas as discussões e análise dos resultados da pesquisa sobre motivação no trabalho voluntário eventual voltado ao esporte, nos jogos olímpicos do Rio de Janeiro, evento ocorrido entre 5 e 21 de agosto de 2016. Este estudo utilizou o modelo teórico de Bang e Chelladurai (2009) como forma de identificar os aspectos motivacionais dos voluntários que atuaram na olimpíada. Serão mostrados os dados sociodemográficos dos voluntários, comportamentos futuros sobre participação e engajamento desses voluntários em eventos esportivos e, por fim, os fatores motivacionais que levam os voluntários a participar de eventos esportivos. Na sequência, a apresentação do perfil sociodemográfico dos voluntários.

O perfil sociodemográfico dos voluntários que participaram das pesquisas sobre motivação no trabalho voluntário nos jogos olímpicos do Rio de Janeiro apresentou as seguintes características, conforme Quadro 1 a seguir.

Quadro 1: Síntese sociodemográfica

\begin{tabular}{|c|c|c|}
\hline Variável & Classe & Percentual \\
\hline Idade média & 35 anos & \\
\hline Renda média & 4 salários mínimos & \\
\hline \multirow{2}{*}{ Gênero } & Masculino & $44 \%$ \\
\cline { 2 - 3 } & Feminino & $56 \%$ \\
\hline \multirow{2}{*}{ Formação acadêmica } & Médio Completo & $5 \%$ \\
\cline { 2 - 3 } & Universitário & $25 \%$ \\
\cline { 2 - 3 } & Superior Completo & $40 \%$ \\
\cline { 2 - 3 } & Pós-Graduação & $30 \%$ \\
\hline Jornada de trabalho & Acima de 30 horas & $70,25 \%$ \\
\hline \multirow{2}{*}{ semanal } & & \\
\hline
\end{tabular}

Fonte: Dados da Pesquisa (2016)

A partir dos dados apresentados, é possível perceber algumas características importantes a serem ressaltadas, como a maior par- 
ticipação de mulheres como voluntárias nos jogos olímpicos do Rio do Janeiro. Outros estudos que abordaram aspectos motivacionais no esporte, como o de Doherty (2005), Banget al. (2008) e Hallmann e Harms (2012), apresentaram resultados divergentes em relação à maior participação voluntária das mulheres nesses eventos.

Ressalta-se, ainda, um alto nível de escolaridade dos participantes da pesquisa, chegando a 95\% o número de voluntários universitários, graduados e pós-graduados. O Quadro 2, a seguir, apresenta os resultados referentes aos comportamentos futuros sobre participação e engajamento desses voluntários em eventos esportivos.

Quadro 2: Comportamentos futuros dos voluntários

\begin{tabular}{|l|c|c|}
\hline \multicolumn{1}{|c|}{ Variável } & Opções & Percentual \\
\hline Gostaria de participar & Sim & $78 \%$ \\
como voluntário em & Não & $23 \%$ \\
\cline { 2 - 3 } outro evento esportivo & & $9 \%$ \\
\hline $\begin{array}{l}\text { Gostaria de me associar } \\
\text { no futuro como }\end{array}$ & Sim & $91 \%$ \\
\cline { 2 - 3 } voluntário em um clube & Não & \\
esportivo & & \\
\hline
\end{tabular}

Fonte: Dados da pesquisa (2016)

Diante dos resultados apresentados, observa-se que os voluntários estão dispostos a participar de outros eventos esportivos, no entanto, não têm pretensão de se associar a algum clube de desporto como voluntário. Diferentemente desta pesquisa realizada na olimpíada no Brasil, que mostrou um baixo nível de intenção de os pesquisados se tornarem voluntários em algum clube esportivo, em outros países como Alemanha, Inglaterra, Estados Unidos e Canadá há, segundo os autores Breuer e Wicker (2011), Taylor et al. (2003) e Dohenty (2005), um elevado nível de adesão voluntária a clubes esportivos. 


\section{MOTIVAÇõES NO TRABALHO VOLUNTÁRIO EVENTUAL NO ESPORTE}

A análise das motivações voluntárias voltadas ao esporte será estruturada a partir das medidas estatísticas voltadas à média amostral, desvio padrão, coeficiente de variância e análise de correlação das variáveis motivacionais referentes ao modelo teórico de Bang e Chelladurai (2009), "expressão de valores", "contatos interpessoais", "desenvolvimento de carreira", "crescimento pessoal", "extrínseco" e "amor ao esporte". O Quadro 3, a seguir, mostra os resultados estatísticos referentes a cada variável.

Quadro 3: Resultados das variáveis motivacionais

\begin{tabular}{|c|c|c|c|c|c|c|c|}
\hline Variável & Questões & $\begin{array}{l}\text { Média } \\
\text { por } \\
\text { Questão }\end{array}$ & $\begin{array}{l}\text { Desvio } \\
\text { Padrão por } \\
\text { Questão }\end{array}$ & $\begin{array}{l}\text { Coeficiente } \\
\text { de Variância } \\
\text { por Questão }\end{array}$ & $\begin{array}{l}\text { Média da } \\
\text { Variável }\end{array}$ & $\begin{array}{l}\text { Desvio } \\
\text { Padrão da } \\
\text { Variável }\end{array}$ & $\begin{array}{l}\text { Coeficiente de } \\
\text { Variância da } \\
\text { Variável }\end{array}$ \\
\hline \multirow{6}{*}{$\begin{array}{l}\text { Expressão } \\
\text { de valores }\end{array}$} & 1 & 7,53 & 1,12 & $14,93 \%$ & \multirow{6}{*}{7,86} & \multirow{6}{*}{1,11} & \multirow{6}{*}{$14,21 \%$} \\
\hline & 2 & 7,63 & 1,05 & $13,79 \%$ & & & \\
\hline & 3 & 8 & 1,22 & $15,25 \%$ & & & \\
\hline & 4 & 8,11 & 1,11 & $13,74 \%$ & & & \\
\hline & 5 & 8,06 & 1,07 & $13,32 \%$ & & & \\
\hline & 1 & 7,54 & 1,15 & $15,47 \%$ & & & \\
\hline \multirow{5}{*}{$\begin{array}{l}\text { Contatos } \\
\text { Interpes- } \\
\text { soais }\end{array}$} & 2 & 7,22 & 1,18 & $16,41 \%$ & \multirow{5}{*}{7,05} & \multirow{5}{*}{1,08} & \multirow{5}{*}{$15,71 \%$} \\
\hline & 3 & 7,23 & 1,01 & $14,04 \%$ & & & \\
\hline & 4 & 6,21 & 1 & $16,90 \%$ & & & \\
\hline & 1 & 6,45 & 1,12 & $17,36 \%$ & & & \\
\hline & 2 & 6,82 & 1,19 & $17,57 \%$ & & & \\
\hline \multirow[t]{4}{*}{ Carreira } & 3 & 6,45 & 1,09 & $17,02 \%$ & \multirow[t]{4}{*}{6,21} & \multirow[t]{4}{*}{1,08} & \multirow[t]{4}{*}{$17,56 \%$} \\
\hline & 4 & 5,98 & 0,99 & $16,67 \%$ & & & \\
\hline & 5 & 5,35 & 1,02 & $19,18 \%$ & & & \\
\hline & 1 & 7,16 & 1,32 & $18,46 \%$ & & & \\
\hline \multirow{3}{*}{$\begin{array}{l}\text { Crescimen- } \\
\text { to pessoal }\end{array}$} & 2 & 6,23 & 1,15 & $18,54 \%$ & \multirow{3}{*}{6,63} & \multirow{3}{*}{1,15} & \multirow{3}{*}{$17,47 \%$} \\
\hline & 3 & 7,01 & 1,13 & $16,13 \%$ & & & \\
\hline & 4 & 6,12 & 1,02 & $16,75 \%$ & & & \\
\hline \multirow{2}{*}{ Extrínseco } & 1 & 3,26 & 0,85 & $26,09 \%$ & \multirow{2}{*}{3,45} & \multirow{2}{*}{0,82} & \multirow{2}{*}{$23,96 \%$} \\
\hline & 2 & 3,64 & 0,79 & $21,83 \%$ & & & \\
\hline \multirow{4}{*}{$\begin{array}{l}\text { Amor ao } \\
\text { Esporte }\end{array}$} & 1 & 8,22 & 1,21 & $14,71 \%$ & \multirow{4}{*}{7,63} & \multirow{4}{*}{1,14} & \multirow{4}{*}{$15,17 \%$} \\
\hline & 2 & 6,91 & 1,22 & $17,77 \%$ & & & \\
\hline & 3 & 7,94 & 1,1 & $13,87 \%$ & & & \\
\hline & 4 & 7,43 & 1,06 & $14,32 \%$ & & & \\
\hline
\end{tabular}

Fonte: Dados da pesquisa (2016) 
Os dados apresentados no Quadro 3 mostram que o maior nível motivacional dos voluntários que atuaram nos jogos olímpicos do Rio de Janeiro está relacionado à variável "expressão de valores" e o menor nível motivacional tem relação com os fatores da variável "extrínseco".

A seguir, as variáveis motivacionais serão analisadas individualmente a partir da ordem das motivações relatadas no Quadro 3.

Quadro 4: Variável motivacional "expressão de valores"

\begin{tabular}{|l|l|l|l|l|l|l|l|}
\hline \multirow{2}{*}{ Variável } & Questões & $\begin{array}{l}\text { Média da } \\
\text { Questão }\end{array}$ & $\begin{array}{l}\text { Desvio } \\
\text { Padrão da } \\
\text { Questão }\end{array}$ & $\begin{array}{l}\text { Coeficiente } \\
\text { de Variância } \\
\text { da Questão }\end{array}$ & $\begin{array}{l}\text { Média da } \\
\text { Variável }\end{array}$ & $\begin{array}{l}\text { Desvio } \\
\text { Padrão } \\
\text { da Va- } \\
\text { riável }\end{array}$ & $\begin{array}{l}\text { Coeficiente } \\
\text { de Va- } \\
\text { riância da } \\
\text { Variável }\end{array}$ \\
\hline \multirow{2}{*}{$\begin{array}{l}\text { Expressão } \\
\text { de valores }\end{array}$} & 1 & 7,53 & 1,12 & $14,93 \%$ & & & \\
\cline { 2 - 5 } & 2 & 7,63 & 1,05 & $13,75 \%$ & \multirow{2}{*}{7,86} & \multirow{2}{*}{1,11} & \multirow{2}{*}{$14,21 \%$} \\
\cline { 2 - 5 } & 4 & 8 & 1,22 & $15,25 \%$ & $13,74 \%$ & & \\
\cline { 2 - 5 } & 5 & 8,11 & 1,11 & $13,32 \%$ & & \\
\hline
\end{tabular}

Fonte: Dados da pesquisa (2016)

A variável motivacional "expressão de valores", constituída por cinco questões constantes no instrumento de pesquisa, apresentou média $(7,86)$, desvio padrão $(1,11)$ e coeficiente de variância $(14,21 \%)$, o que caracteriza uma amostra homogênea, de boa precisão e bem próxima da média, não mostrando dispersão nas respostas apresentadas pelos voluntários pesquisados.

"Expressão de valores" é a variável motivacional mais altruísta do modelo teórico de Bang e Chelladurai (2009), pois está relacionada a aspectos motivacionais, como: sentir-se importante em ajudar os outros, ajudar a criar uma sociedade melhor e contribuir para que o evento esportivo se torne um sucesso. Essa variável apresentou a maior média $(7,86)$ entre todas as analisadas, levando-se ao entendimento que o maior aspecto motivacional dos voluntários nos jogos olímpicos do Rio de Janeiro é "expressão de valores", que possui características altruístas. 
Estudo de Hallmann e Harms (2012), que avaliou os aspectos motivacionais dos voluntários nos jogos nacionais de handebol e equitação na Alemanha, apresentou resultados semelhantes ao identificado nesta pesquisa, em que a variável "expressão de valores" foi o principal fator motivacional dos voluntários nesses eventos esportivos. A seguir, serão relatados os resultados referentes à variável motivacional "contatos interpessoais".

Quadro 5: Variável motivacional "contatos interpessoais"

\begin{tabular}{|l|l|l|l|l|l|l|l|}
\hline \multirow{2}{*}{ Variável } & Questões & $\begin{array}{l}\text { Média da } \\
\text { Questão }\end{array}$ & $\begin{array}{l}\text { Desvio Padrão } \\
\text { da Questão }\end{array}$ & $\begin{array}{l}\text { Coeficiente de } \\
\text { Variância da } \\
\text { Questão }\end{array}$ & $\begin{array}{l}\text { Média da } \\
\text { Variável }\end{array}$ & $\begin{array}{l}\text { Desvio } \\
\text { Padrão da } \\
\text { Variável }\end{array}$ & $\begin{array}{l}\text { Coeficiente de } \\
\text { Variância da } \\
\text { Variável }\end{array}$ \\
\hline \multirow{2}{*}{$\begin{array}{l}\text { Contatos in- } \\
\text { terpessoais }\end{array}$} & 2 & 7,54 & 1,15 & $15,47 \%$ & \multirow{2}{*}{7,05} & \multirow{2}{*}{1,08} & \multirow{2}{*}{$15,71 \%$} \\
\cline { 2 - 7 } & 3 & 7,22 & 1,18 & $16,41 \%$ & & \\
\hline
\end{tabular}

Fonte: Dados da Pesquisa (2016)

Os dados apresentados no Quadro 5 colocam a variável motivacional "contatos interpessoais" com a terceira maior média entre os aspectos motivacionais da pesquisa. Essa variável é constituída por quatro questões constantes no instrumento de pesquisa e apresentou média $(7,05)$, desvio padrão $(1,08)$ e coeficiente de variância $(15,71 \%)$, verificando-se, assim, um resultado consistente de uma amostra que tem características de homogeneidade, boa precisão e que a maioria das respostas apresentadas ficou bem próxima da média verificada na variável.

Essa variável está relacionada a aspectos motivacionais voltados à interação do voluntário com outras pessoas, à disponibilidade em trabalhar com pessoas diferentes, conhecer novas pessoas e desenvolver relacionamentos com outras pessoas, apresentou a média $(7,05)$, indicando o terceiro maior fator motivacional dos voluntários dos jogos olímpicos, verificando-se, assim, que o desenvolvimento da relação interpessoal é um importante fator motivacional para os voluntários da olimpíada no Rio de Janeiro. 
Estudo de Filo et al. (2012), que apresentou uma escala sobre motivação voluntária nos esportes, nos Estados Unidos, mostrou resultados semelhantes aos identificados nesta pesquisa. Na pesquisa realizada nos Estados Unidos, os aspectos motivacionais dos voluntários, voltados às relações interpessoais, assim como nos jogos olímpicos, apresentaram o terceiro maior fator motivacional relatado pelos voluntários. A seguir, serão descritos os dados referentes à variável motivacional "desenvolvimento de carreira".

Quadro 6: Variável motivacional "Desenvolvimento de carreira"

\begin{tabular}{|l|l|l|l|l|l|l|l|}
\hline \multirow{2}{*}{ Variável } & Questões & $\begin{array}{l}\text { Média da } \\
\text { Questão }\end{array}$ & $\begin{array}{l}\text { Desvio } \\
\text { Padrão da } \\
\text { Questão }\end{array}$ & $\begin{array}{l}\text { Coeficiente } \\
\text { de Variância } \\
\text { da Questão }\end{array}$ & $\begin{array}{l}\text { Média da } \\
\text { Variável }\end{array}$ & $\begin{array}{l}\text { Desvio } \\
\text { Padrão da } \\
\text { Variável }\end{array}$ & $\begin{array}{l}\text { Coeficiente } \\
\text { de Variância } \\
\text { da Variável }\end{array}$ \\
\hline \multirow{2}{*}{$\begin{array}{l}\text { Desenvol- } \\
\text { vimento de } \\
\text { carreira }\end{array}$} & 1 & 6,45 & 1,12 & $17,36 \%$ & & \multirow{2}{*}{6,21} & \multirow{2}{*}{1,08} \\
\cline { 2 - 5 }
\end{tabular}

Fonte: Dados da Pesquisa (2016)

A variável motivacional "desenvolvimento de carreira" se relaciona à forma como as atividades voluntárias no esporte podem contribuir para o desenvolvimento da carreira profissional do voluntário. Os resultados apresentados por essa variável motivacional a coloca como a quinta maior média entre as seis variáveis pesquisadas. É constituída por cinco questões constantes no instrumento de pesquisa e apresentou média $(6,21)$, desvio padrão $(1,08)$ e coeficiente de variância $(17,56 \%)$. Embora a média tenha diminuído em relação as outras duas variáveis relatadas, o resultado dessa variável mostra um resultado consistente, com características homogêneas, boa precisão e baixa dispersão entre as respostas dos voluntários submetidos à pesquisa.

Com média $(6,21)$, essa variável motivacional constitui o quinto maior fator motivacional dos voluntários dos jogos olímpicos, observando-se, assim, que o desenvolvimento de carreira não é um 
fator motivacional preponderante para os voluntários que atuaram na olimpíada do Rio de Janeiro.

Estudo de Bang e Ross (2009), que apresentou uma escala sobre motivação voluntária nos esportes, na Grécia, mostrou resultados semelhantes ao identificado nesta pesquisa. Na pesquisa realizada na Grécia, os aspectos motivacionais dos voluntários voltados ao desenvolvimento de carreira, assim como nos jogos olímpicos, apresentou o quinto maior fator motivacional relatado pelos voluntários.

A seguir, serão descritos os dados referentes à variável motivacional "crescimento pessoal".

Quadro 7: Variável motivacional "Crescimento Pessoal"

\begin{tabular}{|c|c|c|c|c|c|c|c|}
\hline Variável & Questões & $\begin{array}{l}\text { Média da } \\
\text { Questão }\end{array}$ & $\begin{array}{l}\text { Desvio } \\
\text { Padrão da } \\
\text { Questão }\end{array}$ & $\begin{array}{l}\text { Coeficiente } \\
\text { de Variância } \\
\text { da Questão }\end{array}$ & $\begin{array}{l}\text { Média } \\
\text { da Va- } \\
\text { riável }\end{array}$ & $\begin{array}{l}\text { Desvio } \\
\text { Padrão } \\
\text { da Va- } \\
\text { riável }\end{array}$ & $\begin{array}{l}\text { Coefi- } \\
\text { ciente de } \\
\text { Variância } \\
\text { da Variá- } \\
\text { vel }\end{array}$ \\
\hline \multirow{4}{*}{$\begin{array}{l}\text { Cresci- } \\
\text { mento } \\
\text { Pessoal }\end{array}$} & 1 & 7,16 & 1,32 & $18,46 \%$ & \multirow{4}{*}{6,63} & \multirow{4}{*}{1,15} & \multirow{4}{*}{$17,47 \%$} \\
\hline & 2 & 6,23 & 1,15 & $18,54 \%$ & & & \\
\hline & 3 & 7,01 & 1,13 & $16,13 \%$ & & & \\
\hline & 4 & 6,12 & 1,02 & $16,75 \%$ & & & \\
\hline
\end{tabular}

Fonte: Dados da Pesquisa (2016)

Os dados expostos no Quadro 7 colocam a variável motivacional "crescimento pessoal", constituída de quatro questões, constante no instrumento de pesquisa, como a quarta maior média frente às seis variáveis pesquisadas. A variável possui média de $(6,63)$, desvio padrão $(1,15)$ e coeficiente de variância $(17,47 \%)$. Esse resultado caracteriza uma amostra homogênea, de boa precisão e bem próxima da média, não mostrando dispersão nas respostas apresentadas pelos voluntários pesquisados.

A variável motivacional "Crescimento pessoal" tem relação com os seguintes aspectos: sentir-se bem ao ser voluntário, desenvolvimento de potencialidades do voluntário e sentir-se importante ao ser voluntário. Com média $(6,63)$, essa variável motivacional constitui o quarto maior fator motivacional dos voluntários dos jogos olímpicos, verificando-se, assim, que o crescimento pessoal não é 
considerado um dos fatores principais que levaram os voluntários a participarem dos jogos olímpicos no Rio de Janeiro.

O mesmo estudo de Banget al. (2008), que definiu uma escala sobre motivação voluntária nos esportes, na Grécia, apresentou resultados semelhantes aos identificados nessa pesquisa. Na pesquisa realizada na Grécia, os aspectos motivacionais dos voluntários voltados ao crescimento pessoal, assim como nos jogos olímpicos, mostrou o quarto maior fator motivacional relatado pelos voluntários.

A seguir, serão descritos os dados referentes à variável motivacional "extrínseco".

Quadro 8: Variável motivacional "Extrínseco"

\begin{tabular}{|l|l|l|l|l|l|l|l|}
\hline Variável & Questões & $\begin{array}{l}\text { Média } \\
\text { da } \\
\text { Questão }\end{array}$ & $\begin{array}{l}\text { Desvio } \\
\text { Padrão da } \\
\text { Questão }\end{array}$ & $\begin{array}{l}\text { Coeficiente } \\
\text { de Variância } \\
\text { da Questão }\end{array}$ & $\begin{array}{l}\text { Média } \\
\text { da Va- } \\
\text { riável }\end{array}$ & $\begin{array}{l}\text { Desvio } \\
\text { Padrão } \\
\text { da Variá- } \\
\text { vel }\end{array}$ & $\begin{array}{l}\text { Coefi- } \\
\text { ciente de } \\
\text { Variância } \\
\text { da Variá- } \\
\text { vel }\end{array}$ \\
\hline \multirow{2}{*}{$\begin{array}{l}\text { Extrín- } \\
\text { seco }\end{array}$} & 1 & 3,26 & 0,85 & $26,09 \%$ & 3,45 & 0,82 & $23,96 \%$ \\
\cline { 2 - 7 } & 2 & 3,64 & 0,79 & $21,83 \%$ & 39 & \\
\hline
\end{tabular}

Fonte: Dados da Pesquisa (2016)

A variável motivacional "extrínseco" apresentou-se como a menor motivação dos voluntários que participaram dos jogos olímpicos no Rio de Janeiro. Essa variável é constituída por duas questões do questionário de pesquisa e tem relação com a aquisição de material e produtos licenciados do evento esportivo, assim como receber gratuitamente ingressos para acompanhar o evento. Na perspectiva do modelo teórico de Bang e Chelladurai (2009), essa variável possui a maior motivação egoísta entre as seis variáveis pesquisadas.

Com média $(3,45)$, desvio padrão $(0,82)$ e coeficiente de variância de $(23,96 \%)$, pode-se concluir que os voluntários que participaram dos jogos olímpicos não possuem motivações egoístas. Ressalta-se, porém, que o coeficiente de variância apresentou um resultado relativamente alto, o que caracteriza essa amostra como de baixa precisão. Estudo de Hallmann e Harms (2012) em eventos esportivos na Alemanha apresentou resultados semelhantes a este estudo, visto que a variável motivacional "extrínseco" foi o menor 
aspecto motivacional apresentado pelos voluntários em ambas as pesquisas. A seguir, serão relatados os resultados referentes à variável motivacional "amor ao esporte".

Quadro 9: Variável motivacional "Amor ao Esporte"

\begin{tabular}{|l|l|l|l|l|l|l|l|}
\hline Variável & $\begin{array}{l}\text { Ques- } \\
\text { tões }\end{array}$ & $\begin{array}{l}\text { Média da } \\
\text { Questão }\end{array}$ & $\begin{array}{l}\text { Desvio } \\
\text { Padrão da } \\
\text { Questão }\end{array}$ & $\begin{array}{l}\text { Coeficiente } \\
\text { de Variância } \\
\text { da Questão } \\
1,21\end{array}$ & $\begin{array}{l}\text { Média } \\
\text { da Va- } \\
\text { riável }\end{array}$ & $\begin{array}{l}\text { Desvio } \\
\text { Padrão } \\
\text { da Variá- } \\
\text { vel }\end{array}$ & $\begin{array}{l}\text { Coeficien- } \\
\text { te de Va- } \\
\text { riância da } \\
\text { Variável }\end{array}$ \\
$\begin{array}{l}\text { Amor ao } \\
\text { esporte }\end{array}$ & 2 & 8,22 & $\begin{array}{l}1,21 \% \\
17,77 \%\end{array}$ & 1,22 & 7,63 & 1,14 & $15,17 \%$ \\
& 3 & 7,94 & 1,1 & $13,87 \%$ & $14,32 \%$ & & \\
\hline
\end{tabular}

Fonte: Dados da Pesquisa (2016)

A partir dos resultados verificados no Quadro 9, constatou-se que essa variável apresentou o segundo maior fator motivacional dos voluntários que atuaram nos jogos olímpicos. Exibindo média $(7,63)$, desvio padrão $(1,14)$ e coeficiente de variância $(15,17 \%)$, verifica-se que essa amostra possui boa média, baixa dispersão dos dados e boa confiabilidade, caracterizando, assim, que a variável motivacional "amor ao esporte" é relevante em termos motivacionais para os voluntários que atuaram nas olimpíadas.

Essa variável possui quatro questões constantes no questionário de pesquisa e tem relação com a afinidade e disposição dos voluntários em participar de eventos esportivos. Estudo de Doherty (2005) sobre motivação no trabalho voluntário em clubes esportivos no Canadá mostrou resultado divergente do apresentado nesta pesquisa, no que concerne à variável motivacional "amor pelo esporte". Enquanto na olimpíada do Rio de Janeiro a variável motivacional "amor ao esporte" obteve o segundo maior fator motivacional, na pesquisa de Doherty (2005), a variável "amor ao esporte" ficou como o quinto fator motivacional dos voluntários. A seguir, serão relatados os resultados sobre os dados sociodemográficos e a diferença entre grupos. 


\section{ANÁLISE ENTRE OS DADOS SOCIODEMOGRÁFICOS E A DIFERENÇA ENTRE GRUPOS}

Nesse item serão abordados aspectos relacionados à diferença entre grupos estatisticamente significativos e os dados sociodemográficos constantes no instrumento de pesquisa validado pelo modelo teórico desenvolvido por Bang e Chelladurai (2009).

A seguir, será relatada a diferença entre gênero e a variável “esporte é algo que eu amo (esporte 3)".

Tabela 2: Diferença entre grupos de gênero x "esporte 3"

\begin{tabular}{lcc}
\hline Diferença entre grupos & Média para mulheres & Média para homens \\
\hline Gênero x Esporte 3 & 8,06 & 7,8 \\
\hline
\end{tabular}

Fonte: Dados da pesquisa (2016)

Verifica-se, por intermédio dos dados apresentados na Tabela 2, e levando-se em consideração os aspectos relacionados à variável "esporte 3", constante no instrumento de pesquisa, que, em média, as mulheres são mais propensas a serem voluntárias em eventos esportivos por gostar mais de esporte do que os homens. Estudo de Van Schien et al. (2014), em eventos esportivos na Suíça, evidencia que as mulheres participam mais de eventos esportivos no trabalho voluntário que os homens.

A partir dos dados apresentados, é possível subsidiar os gestores de eventos esportivos para concentrar maiores esforços no recrutamento de mulheres para esses eventos, levando-se em consideração a particularidade de cada atividade esportiva.

A seguir, será relatada a diferença entre grupos da variável idade $\mathrm{x}$ "contatos interpessoais 2 ".

Tabela 3: Diferença entre grupos da variável idade $x$ contatos interpessoais 2

\begin{tabular}{lcc}
\hline Diferença entre grupos & 18-28 anos & acima de 50 anos \\
\hline Idade x “Interpessoal 2" & 7,24 & 7,75 \\
\hline
\end{tabular}

Fonte: Dados da pesquisa (2016) 
Observa-se, a partir dos resultados apresentados na Tabela 3 que fazem relação entre a idade dos voluntários e a variável "interpessoal 2" do instrumento de pesquisa, que os mais velhos tendem a ter uma maior disposição para trabalhar com pessoas diferentes no desenvolvimento de sua atividade voluntária no esporte do que os mais jovens.

Para Pereira (2008), os idosos buscam, em seu trabalho, entre outros fatores, uma oportunidade de construção de uma nova rede de amizades. Nesse sentido, os mais idosos seriam bem aproveitados nos eventos esportivos em atividades nas quais eles tenham contato diretamente com as pessoas.

A seguir, será relatada a diferença entre grupos da variável idade x "carreira 2"

Tabela 4: Diferença entre grupos da variável idade $x$ "carreira 2

\begin{tabular}{lcc}
\hline Diferença entre grupos & $18-28$ anos & acima de 50 anos \\
\hline Idade x "carreira 2" & 5,35 & 2,58 \\
\hline
\end{tabular}

Fonte: Dados da pesquisa (2016)

A variável "carreira 2" diz respeito à disposição que os voluntários possuem para adquirir alguma experiência prática. Nesse sentido, os resultados apresentados na Tabela 4 mostram que os voluntários mais jovens estão mais propensos a se voluntariar no esporte para adquirir alguma experiência prática, se comparados com os mais velhos.

Segundo Gravilov (2012), os jovens buscam desenvolver atividades voluntárias como forma de aprender algo. Como consequência desse resultado, os gestores voltados a eventos esportivos poderiam alocar os voluntários mais jovens, em atividades que pudessem oferecer uma experiência prática, como trabalhos voltados à área de informática da competição, assim como no media Center e na área de logística do evento. A seguir, será relatada a diferença entre grupos da variável nível de escolaridade $\mathrm{x}$ "crescimento 2 ". 
Tabela 5: Diferença entre grupos da variável nível de escolaridade $x$ "crescimento 2"

\begin{tabular}{lcc}
\hline Diferença entre grupos & Nível médio & pós-graduado \\
\hline escolaridade x "crescimento 2" & 6,95 & 5,11 \\
\hline
\end{tabular}

Fonte: Dados da pesquisa (2016)

A variável "crescimento 2" revela aspectos relacionados à possibilidade de o voluntário poder explorar suas próprias potencialidades como um fator motivacional. Percebe-se, a partir dos resultados apresentados, que os voluntários que possuem nível médio como grau de escolaridade estão mais propensos a compreender que a atividade voluntária voltada ao esporte pode fazer que eles utilizem melhor suas potencialidades em relação aos voluntários que têm pós-graduação como nível de escolaridade.

Pode-se inferir, portanto, que as pessoas que possuem pós-graduação entendem que as atividades no trabalho voluntário em um evento esportivo não conseguem explorar suas potencialidades como um todo. Segundo o Modelo teórico de Walton (1973), que aborda aspectos voltados à qualidade de vida no trabalho, existem algumas características que concernem à exploração da potencialidade do funcionário, a saber: significado da tarefa executada, identidade com a tarefa e variedade de habilidades.

Diante desse aspecto, deve existir uma compreensão por parte dos gestores desses eventos, no sentido de alocar os voluntários a partir de uma prévia análise de suas experiências e capacidades, no desenvolvimento de atividades voluntárias, que possibilitem uma melhor exploração de suas potencialidades.

A seguir, será relatada a diferença entre grupos da variável jornada de trabalho $\mathrm{x}$ "esporte 1 ". 
Tabela 6: Diferença entre grupos da variável jornada de trabalho $x$ "esporte 1"

\begin{tabular}{lcc}
\hline Diferença entre grupos & 11-20 horas & acima de 30 horas \\
\hline jornada de trabalho x "esporte 1" & 7,71 & 8,29 \\
\hline
\end{tabular}

Fonte: Dados da pesquisa (2016)

A variável "esporte 1" tem relação com o prazer que o voluntário sente em participar de qualquer evento relacionado ao esporte. Observa-se, por meio dos resultados apresentados, que os voluntários que realizaram suas atividades acima de 30 horas semanais nos jogos olímpicos do Rio de Janeiro, têm mais apreço por eventos relacionados ao esporte se comparados aos voluntários que trabalharam entre 11 e 20 horas semanais no mesmo evento.

Segundo Paula (2002), as pessoas dedicam mais tempo às atividades que lhes proporcionam prazer. Geralmente, essas tarefas estão relacionadas àquelas em que elas estão motivadas a fazer. Diante desse contexto, faz-se necessária uma análise por parte dos gestores envolvidos com eventos esportivos, no sentido de buscar identificar os voluntários que possuem mais afinidade com as modalidades do evento, no intuito de administrar as horas trabalhadas pelos voluntários.

A seguir, será relatada a diferença entre grupos da variável renda $x$ expressão de valores 5 .

Tabela 7: Diferença entre grupos da variável renda $x$ "expressão de valores 5"

\begin{tabular}{lcc}
\hline Diferença entre grupos & sem salário & $1-3$ salários \\
\hline Renda $x$ valores 5 & 8,5 & 7,09 \\
\hline
\end{tabular}

Fonte: Dados da pesquisa (2016)

Diante dos dados apresentados e tendo como referência a variável "expressão de valores 5", constante no instrumento de pesquisa, conclui-se que, em média, os voluntários no esporte que 
não possuem renda são mais propensos em afirmar que o trabalho voluntário ajuda a criar uma sociedade melhor.

Os voluntários, além de contribuir para uma sociedade mais justa, utilizam o trabalho voluntário como forma de melhorar seus currículos em busca de emprego (REVISTA BRASIL, 2015). Esse resultado mostra que é mais vantajoso para os gestores de eventos esportivos recrutar voluntários no esporte que não têm renda, pois estes entendem que a atividade voluntária ajuda na criação de uma sociedade melhor, se comparados aos voluntários que possuem renda entre 1 a 3 salários.

\section{CONSIDERAÇõES FINAIS}

O objetivo deste estudo foi identificar os fatores motivacionais dos voluntários eventuais envolvidos com eventos esportivos no Brasil. O conhecimento sobre a motivação voluntária é essencial no processo de recrutamento dos voluntários nos eventos esportivos. Os gestores desses eventos devem buscar identificar uma correspondência entre os interesses e habilidades dos voluntários com suas atividades nos eventos esportivos.

Diante dos resultados observados na pesquisa, foi possível constatar que as maiores motivações dos voluntários que atuaram nos jogos olímpicos do Rio de Janeiro estão relacionadas às variáveis "expressão de valores", que possui um viés altruísta, "amor ao esporte" e "contatos interpessoais". Como menor fator motivacional dos voluntários, foi identificada a variável "extrínseco", que tem um caráter mais egoísta em termos de motivação voluntária.

Observaram-se, ainda, resultados mais pontuais sobre a pesquisa, que serão descritos a seguir: as mulheres são mais propensas a serem voluntárias em eventos esportivos que os homens; as pessoas

- com maior idade tendem a ter uma maior disposição para trabalhar com pessoas diferentes; os mais jovens tendem a se voluntariar em eventos esportivos para adquirir experiência prática em relação às pessoas mais velhas; os voluntários com menor grau de instrução são mais propensos a compreender que a atividade voluntária pode fazer que eles utilizem melhor suas potencialidades; aqueles voluntários que têm maior apreço pelo esporte tendem a dedicar maior tempo nessa atividade voluntária e os voluntários que não têm renda são 
mais propensos em afirmar que o trabalho voluntário ajuda a criar uma sociedade melhor.

A principal limitação desta pesquisa está relacionada com a concentração de entrevistas em locais específicos. A ideia inicial dos pesquisadores era realizar amostras em todos os locais onde estivessem ocorrendo eventos esportivos, mas, devido à distância entre os locais dos eventos, as pesquisas foram realizadas apenas no centro olímpico e no golfe olímpico.

No que concerne aos estudos futuros, recomenda-se que sejam realizadas pesquisas com voluntários em outros eventos esportivos, tais quais os jogos da juventude e a fórmula 1, eventos que acontecem todos os anos no Brasil e que concentram um bom quantitativo de voluntários. Essas pesquisas poderão ser utilizadas para comparar as motivações no trabalho voluntário eventual nos esportes, como os resultados obtidos nos jogos olímpicos do Rio de Janeiro.

\section{REFERÊNCIAS}

ANHEIER, H. K. E SALAMON, L. M. (1999). “Volunteering in cross-national perspective: Initial comparation". Law and contemporary problems, 62(4): 43-66.

ANNAN, C. SPORT CONGRESS. Congresso Internacional Voluntariado. Laussane, p. 4, 2001. AÑÒ, V. La importância del voluntariado en um gran evento: El programa de Almería 2005. Actas Del Congresso Internacional Andalucia Tierra Del Desporte. Sevilha, v. 2, Consejería de turismo y desporte, 2003.

BACELAR, S. M. (1999). Amostragem nas ciências sociais - relatório de aula teórico -prático. Porto, Portugal.

BANG, H. \& CHELLADURAI, P. (2009). Development and validation of the volunteer motivations scale for international sporting events (VMS-ISE). International Journal of Sport Management, 6, 332-350.

BANG, H., \& ROSS, S. (2009). Volunteer motivation and satisfaction. Journal of venue and Event Management, 1, 61-77.

BARBETTA, P. A. (2004). Estatística Aplicada a Ciências Sociais, 5. ed. Florianópolis: Editora da UFSC.

BARELI, P; LIMA, A. J. F. S. A importância social no desenvolvimento do trabalho voluntário. Revista ciências gerenciais: v. 14, n. 20, ano 2010.

BONJEAN, CHARLES M., WILLIAM T. MARKHAM, and PATRICK O. MACKEN, (1994). "Measuring Self-Expression in Volunteer Organizations: A Theory-Based Questionnaire." Journal of Applied Behavioral Science, 30 (4), 487-515. 
BREUER, C. and WICKER, P. (2011). "Situation und entwicklung des freiwilligen engagements und ehrenamts in sportverein "In: Breuer, C. (Org.) sportenwicklungsbericht 2009/2010 - Analysezur situation der sportvereine in Deuschland, sportveilogstraub, koln, p. 91-111.

BRUNO, B. FIORILLO, D. (2012). Why without pay? Intrinsic motivation in the unpaid labour supply. Journal of Socio-Economics 41: 659-669.

CNAAN, R.A.; CASCIO, T. Performance and commitement issues in managment of volunteers in human service organizations, journal of social service research, vol. 24, no 314 , pp. 1-37, 1998.

CAVALCANTE, C.E. motivação no trabalho voluntário. expectativas e motivos na pastoral da criança. tese de doutorado, Programa de pós-graduação em administração, Universidade Federal do Rio Grande do Norte, Natal, 2012.

COI (2016). Disponível em: < https://editorolimpico.wordpress.com/2015/06/28/a-evolucaodos-voluntariados-olimpicos-e-o-conceito/, acessado em 10/11/2016.

DOHERTY, A. (2005). A profile of community sport volunteers/volunteer management in community sport clubs. Toronto: parks and recreation Ontario/ sport alliance of Ontario.

FARRELL, J. M., JOHNSTON, M. E., \& TWYNAM, D. G. (1998).Volunteer motivation, satisfaction, and management at an elite sporting competition. Jornal of Sport Management, $12,288-300$.

FIFA (2014). Disponível em: <http://www.brasil.gov.br/esporte/2012/09/programa-de-voluntarios-da-copa-2014-recebeu-mais-de-130-mil-inscricoes $>$, acessado em 10/11/2016.

FILO K., GROZA MD, Fairley S. The role of belief in making a difference inenhancing attachment to a charity sport event. J Nonprofit Public SectorMark 2012, 24 (2): 123-140.

GRAVILOV, G. (2012). Managing sport event volunteers: London 2012 Olympic Games Marers.

HALLMANN, K.; HARMS, G. (2012). “Determinants of volunteer motivation and their impact on future voluntary engagement: A comparison of volunteer's motivation at sport events in equestrian and handball." International Journal of Event and Festival Management, v. 3, iss 3, p. 272-291.

JOHNSTON, M., E., TWYNAM, D. G., \& FARRELL, J. M. (1998). Motivation and satisfaction of event volunteers for a major youth organization . Leisure/Loisir, 24 (1-2), 161-177.

KOUTROU, NIKI (2014). Measuring Olympic Volunteers' Motivations. Intersections and Intersectionalities in Olympic and Paralympic Studies, p. 55-61.

LATHSM, G.P., Pinder, C.C. Work Motivation Teory and research at the dawn of the twenty-first century. Annual review of psychology, 56, 485-516, 2005.

MACDUFF, NANCY (1991). Episodic Volunteering: Building the Short-Term Volunteer Program. WallaWalla, WA: MBA Publishing.

MORAGAS, M. Evolution of the Olympic Volunteers in the Olympic Games. In: MC ALOON, John. Volunteers, Global Society and the Olympic Moviment. Simpósio Internacional. Laussane, 2001. 
PALASSI, M. P., \& VERVLOET, A. M. P. (2011). Eleições, mesários e subjetividade: reflexões sobre a produção de sentidos subjetivos a partir da participação voluntária no processo de votação. Psicologia e Sociedade, 23(2), 312-324.

PAULA, E. DE. Bom Sucesso. Relações interpessoais e qualidade de vida no trabalho. Rio de Janeiro: Quality Mark Ed., 2002.

PEREIRA, P. A. P. Discussões conceituais sobre política social como política pública e direito de cidadania. In: Política Social no Capitalismo: Tendências Contemporâneas. São Paulo: Cortez, 2008.

PIMENTEL GOMES, F. Curso de Estatística Experimental, 14. ed. Piracicaba Desgapari, 200, 477p.

REVISTA BRASIL (2015). Disponível em: <http://www.ebc.com.br/cidadania/2015/09/empregosaiba-como-o-trabalho-voluntario-pode-valorizar-o-seu-curriculo>, acessado em 08/03/2017.

RUBIN, A., \& THORELLI, I. M. (1984). Egoistic motives and longevity of participation by service volunteers. Journal of Applied Behavioral Science, 20 (3), 223-235.

STYERS, D. (2004).Volunteering for success. Australian Journal on Volunteering, 9 (2), 84-86.

TADINI, R. F. Voluntariado em Eventos Esportivos Especiais no Brasil: Uma Análise da Capacitação de Voluntários Promovida pelo Comitê Olímpico Brasileiro. XXX Congresso Brasileiro de Ciências da Comunicação - Santos - 29 de agosto a 2 de setembro de 2007.

TAMAYO. A. PASCHOAL, T. Impacto dos valores laborais e da interferência da família: trabalho no estresse ocupacional. Psic.: teor. e pesq., n.21, v.2, maio 2005.

TAYLOR, P., NICHOLS, G., HOLMES, K., JAMES, M., GRATTON, C., GARRETT, R., KOKOLAKAKIS, T., MULDER, C., \& KING, L. (2003). Sports volunteering in England. London: Sport England.

VAN SCHIE S., GUNTERT ST, OOSTLANDER J. et al. How the organizational context impacts volunteers: a differentiated perspective on self-determined motivation. Int Soc Third Sector Res 2014.

WALTON, R. Quality of working life: what is it? Slow Management Review. USA, v. 15, n. 1, p. 11-21, 1973.

WANG, C. L., \& WU, X. (2014). Volunteers' motivation, satisfaction, and management in large-scale events: an empirical test from the 2010 shanghai world expo. voluntas, 25, 754-771.

Recebido em: 13-04-2017

Aprovado em: 15-09-2017

Avaliado pelo sistema double blind review.

Editor: Coordenação do PPGA/UMESP

Disponível em http://mjs.metodista.br/index.php/roc 